\title{
Resolution of pancreatic ascites with octreotide
}

\author{
J A Rushforth, J M Beck, M McMahon, J W L Puntis
}

\begin{abstract}
A 7 month old infant with pancreatitis and ascites was managed successfully with subcutaneous octreotide and external drainage of a pseudocyst. An endoscopic retrograde cholangiopancreatographic examination showed no congenital abnormality and was consistent with chronic pancreatitis. Octreotide has a possible therapeutic role in pancreatic ascites.
\end{abstract}

\section{(Arch Dis Child 1993;68:135-6)}

Pancreatitis in infants and children is a rare but serious condition and presents a complex challenge to clinicians. Trauma is the most common aetiology, however the causes are diverse. Management is supportive and includes bowel rest and parenteral nutrition. More recently, the use of pancreatic secretory inhibitors has been advocated.

\section{Case report}

A boy of 7 months was admitted with a short history of irritability. Over the next 24 hours his condition deteriorated and he developed ascites. Abdominal paracentesis revealed haemorrhagic fluid with a high amylase content (2200 IU/l). Serum amylase at this time, 72 hours after the onset of symptoms, was $110 \mathrm{IU} / 1$ (normal range 15-95 IU/l).

Acute pancreatitis with pancreatic ascites was diagnosed and medical management commenced with nasogastric suction, intravenous fluids, and antibiotics.

Despite full supportive treatment the child's clinical condition continued to deteriorate. He developed severe respiratory embarrassment secondary to increasing ascites. Repeated paracentesis was required and $1400 \mathrm{ml}$ of ascitic fluid were removed over a 10 day period. The ascitic fluid remained bloodstained and had a high amylase content (over 1000 IU/l).

at Leeds,

Department of

Paediatrics and

Child Health

J A Rushforth

J W L Puntis

Department of

Paediatric Surgery

J M Beck

Department of Surgery

M McMahon

Correspondence to:

Dr J A Rushforth,

Department of Paediatrics

and Child Health,

The General Infirmary

The General
at Leeds,

at Leeds,

Belmont Grove,
Leeds LS2 9NS.

Accepted 15 September 1992
CLINICAL PROGRESS

Institution of subcutaneous octreotide therapy (15 $\mu \mathrm{g}$ twice a day) resulted in a dramatic decrease in the production of ascites such that further paracentesis was not required.

Serial ultrasound and computed tomography showed an oedematous pancreas and a gradually enlarging pancreatic pseudocyst. This was drained under ultrasound control by insertion of a percutaneous catheter into the cyst through the body of the stomach. Subsequent ultrasound scans showed full resolution of the pseudocyst. Enteral feeds were reintroduced without relapse and the child made a complete and uneventful recovery.

An endoscopic retrograde cholangiopancreatographic examination performed six weeks after resolution of symptoms showed normal pancreatic anatomy but diffuse dilatation of the duct consistent with chronic pancreatitis.

There has been no recurrence of symptoms over a 12 month follow up period and exocrine pancreatic function monitored by serial faecal chymotrypsin concentrations remains normal.

\section{Discussion}

Acute pancreatitis is unusual in childhood and may present with abdominal pain and ascites. The diagnosis is confirmed by finding a high amylase value in either blood or ascitic fluid. Up to $30 \%$ of cases may not be discovered until postmortem. ${ }^{1}$

Both accidental and non-accidental injury are important causes of pancreatitis. Infections such as mumps, enterovirus, and mycoplasma have also been implicated. Multisystem disorders including Reye's syndrome, haemolytic uraemic syndrome, and systemic lupus erythematosus can all be associated with acute pancreatitis, ${ }^{2}$ as can metabolic disorders such as organic acidaemias, cystic fibrosis, hyperparathyroidism, and hyperlipidaemia types I, IV, and V. Drugs which can cause acute pancreatitis include high dose steroids, azathioprine, and metronidazole. Congenital abnormalities of the pancreas are said to be associated with increased risk of pancreatitis, however a proportion of cases remain idiopathic.

Ascites develops from leakage of pancreatic juice either directly into the peritoneal cavity through a breach in the duct or by communication with a pseudocyst. Damage to the duct may follow trauma or be secondary to acute inflammation. Pleural or pericardial effusions can occur. ${ }^{3}$

When medical management has failed to control ascites, a surgical drainage procedure is usually required. This is associated with a significant mortality and the use of octreotide may reduce the need for surgical intervention. 
Octreotide is a synthetic octapeptide analogue of somatostatin and shares its biological activity as a result of four common amino acids. The mode of action seems to be at two levels, by a direct receptor specific inhibition of adenylcyclase activity and by inhibition of calcium flux across cell membranes. The exact physiological role of somatostatin and octreotide on the gastrointestinal tract has not been precisely defined, however, somatostatin and octreotide can be regarded as 'pan inhibitors' of gastrointestinal, pancreatic exocrine, and endocrine functions, and gastrointestinal motility. ${ }^{4}$ Action on the human pancreas appears to be by a reduction of enzyme secretion, with no reduction in bicarbonate secretion. ${ }^{5}$

Octreotide's advantage over somatostatin is a much longer half life ( 1 to 2 hours compared with only 2 minutes). It can therefore be given by subcutaneous injection rather than continuous infusion. Somatostatin has been used with some benefit in the management of pancreatitis in adults, ${ }^{6}$ although further trials are needed to establish its exact role in treatment.

In our patient octreotide treatment resulted in a marked reduction in the production of ascitic fluid and improvement in the condition of the child. No side effects were seen. We suggest that octreotide may have a place in children with acute pancreatitis and its complications. The long term prognosis in this patient is uncertain but treatment with free radical scavengers has a possible role in preventing recurrence. $^{7}$

We would like to thank Dr D Kelly and Dr J M Braganza for their help with investigations and management.

1 Buntain WL, Wood JB, Woolley MM. Pancreatitis in childhood. F Pediatr Surg 1978;13:143-9.

2 Weitzman Z, Durie PR. Acute pancreatitis in childhood. f Pediatr 1988;113:24-9.

3 Mucklow ES, Freeman NV. Pancreatic ascites in childhood. Br f Clin Pract 1990;44:248-51.

4 Burroughs AK, McCormick PA. Somatostatin and octreotide in gastroenterology. Alimentary Pharmacology and Therapeutics 1991;5:331-41

5 Layer P, vd Ohde M, Muller MK, Beglinger C. Effects of somatostatin on the exocrine pancreas. Scand $\mathcal{F}$ Gastroenterol 1991;26:129-36.

6 D'Amico D, Favia G, Biasiato R, et al. The use of somatostatin in acute pancreatitis-results of a multicenter trial. Hepatogastroenterology 1990;37:92-8.

7 Uden S, Schofield D, Miller PF, Day JP, Bottiglier T, Braganza JM. Antioxidant therapy for recurrent pancreatitis; biochemical profiles in a placebo-controlled trial. Alimentary Pharmacology and Therapeutics 1992;6:229-40.

\title{
Fructose breath hydrogen tests
}

\author{
J H Hoekstra, A A M W van Kempen, S B Bijl, C M F Kneepkens
}

\begin{abstract}
Fructose absorption was studied by the breath hydrogen test in 114 healthy children aged $0.1-6$ years, given either $2 \mathrm{~g} / \mathrm{kg}$ or $1 \mathrm{~g} / \mathrm{kg}$ of fructose. All 57 children given $2 \mathrm{~g} / \mathrm{kg}$ had peak breath hydrogen excretions $\geqslant 20 \mathrm{ppm}$. At $1 \mathrm{~g} / \mathrm{kg}$ only $25 / 57$ (44\%) showed incomplete absorption and the percentage incompletely absorbing fructose and the peak breath hydrogen value were significantly higher in children aged 1-3 years. Interestingly, this age distribution correlates with that of toddler diarrhoea.
\end{abstract}

\section{(Arch Dis Child 1993;68:136-8)}

\author{
Department of \\ Paediatrics, \\ Bosch Medicentrum, \\ PO Box 90153, \\ $5200 \mathrm{ME}$ \\ 's-Hertogenbosch, \\ The Netherlands \\ J H Hoekstra \\ A A $M$ W van Kempen \\ S B Bijl

\section{Department of} \\ Paediatrics, \\ Free University Hospital, \\ Amsterdam, \\ The Netherlands \\ C M F Kneepkens \\ Correspondence to: \\ Dr Hoekstra. \\ Accepted 9 September 1992
}

It has been shown by means of the breath hydrogen test that intestinal absorptive capacity for fructose is limited, partly depending on the presence of glucose. ${ }^{1}$ Malabsorption of fructose would have clinical consequences, especially for toddlers, as they may consume relatively large amounts of apple juice. Discussion continues as to whether incomplete absorption of fructose in young children is normal, as opposed to a specific absorption defect. ${ }^{23}$ We therefore reinvestigated fructose absorption, using the breath hydrogen test, in children under 6 years of age.

\section{Subjects and methods}

The study group comprised 114 healthy children
(59 boys). Mean age was 3.5 years (range $0 \cdot 1-6 \cdot 0)$. They were recruited from day care centres and kindergartens. The parents completed a questionnaire concerning actual diets and bowel habits.

Fifty seven children each were given $2 \mathrm{~g} / \mathrm{kg}$ or $1 \mathrm{~g} / \mathrm{kg}$ of fructose as a $20 \%$ solution after at least a six hour fast. The two groups were comparable in terms of age and sex. Breath samples were taken before fructose ingestion and at 30 minute intervals until 2.5 hours after ingestion and analysed using the Lactoscreen (Hoek Loos) breath tester. An increase in breath hydrogen of at least $20 \mathrm{ppm}$ over baseline was considered indicative of incomplete absorption of fructose. During the test and for two hours thereafter the children were observed for the presence of abdominal discomfort or diarrhoea.

The results are expressed as mean (SEM). Statistical analysis was performed using the $\chi^{2}$ test and Student's $t$ test for unpaired data (two sided).

\section{Results}

All 57 children given fructose at $2 \mathrm{~g} / \mathrm{kg}$ had breath hydrogen increases $\geqslant 20$ ppm over baseline. Breath hydrogen increases varied from 21 to $146 \mathrm{ppm}$ (mean (SEM) 64 (4) ppm; fig 1); there was no significant relation with age (fig 2A). Symptoms were noted in 12 children: abdominal pain in four and diarrhoea in three, five children experiencing both. Peak breath 